\title{
A Reforma Luterana e suas relações com a educação
}

Recebido: 06/07/2016. Aprovado: 15/07/2016.

\author{
Martha Regina Maas* \\ Katilene Willms Labes**
}

Resumo: Em 1517, ao afixar suas teses na porta da igreja do castelo de Witenberg, Lutero não fazia ideia das mudanças no campo da educação, que hoje são constatadas como desencadeadas a partir do movimento da Reforma. Ele próprio passou pela experiência de uma educação severa, marcada por castigos físicos. A forma de debate estudantil na universidade preparou-o para os embates polêmicos de sua luta reformadora. Na sua "Carta aberta" sobre a reforma da Cristandade, em 1520, ele propôs também a reforma das Universidades. Sua tradução da Bíblia para o alemão fluente foi uma contribuição importante, mesmo decisiva, para as mudanças no sistema educacioal. Seu modelo de educação incentivou e construiu uma sociedade mais crítica, influindo também nas comunidades luteranas imigradas para o sul do Brasil no século XIX.

Palavras-chave: Educação. Mudança. Reforma. Debate. Crítica.

Abstract: In 1517, when he affixed his theses at the door of the church of Witenberg castle, Luther had no idea of the changes in the field of education which today are recognized as proceeding from the Reformation movement. Luther himself had the experience of a severe education, marked by physical punishments. The method of public discussion in the university prepared him to the polemical clashes of his reforming struggle. In his "Open Letter" about the reform of Christianity, in 1520, he proposed also the reform of the universities. His translation of the Bible to the German language was a very important, even decisive, contribution to the changes in the educational system. His model of education encouraged and built a more critical society, having influence also in the Lutheran communities immigrated to the south of Brasil in the XIX century.

Keywords: Education. Change. Reform. Discussion. Critics.

* $\quad$ Mestre em Educação, FURB, Blumenau, SC. Graduada em Letras.

** Mestranda em Teologia, Faculdades EST, São Leopoldo, RS. 
Quando, em 1517, Martin Luther pregou seus escritos na porta da Igreja do Castelo de Wittenberg, não tinha clareza sobre as mudanças no campo da educação que hoje são constatadas como desencadeadas a partir do movimento da Reforma. Filho do minerador João Luther e da Dona de casa Margaretha Lindemann, Lutero recebeu uma educação informal bastante severa, para a qual ele próprio atribuiu sua timidez. Os castigos eram constantes, duros e também físicos. Entretanto, o reformador destacou, mais tarde, que as ações dos seus pais não foram motivadas pelas suas intenções, pois seus objetivos eram os melhores e suas ações eram a forma que compreendiam necessárias para alcançar o desejo de lhe oferecer boa educação.

No âmbito de sua educação formal, Lutero ingressou na Escola Latina, no ano de 1491, aos sete anos de idade, na cidade de Mansfeld, onde estudou especialmente gramática, mas também um pouco de lógica, retórica e música. Na escola, ele também sofria com castigos que muitas vezes o agrediam fisicamente, os quais foram relatados em diferentes escritos. Lindberg relata a respeito das técnicas utilizadas, que reforçavam o medo e envergonhavam os alunos:

As técnicas pelas quais foi forçado a aprender latim como base para estudos posteriores incluíam a coerção e a ridicularização. Alunos despreparados eram forçados a exibir a imagem de um jumento e eram tratados como jumentos. Um aluno que falasse alemão em vez de latim em aula apanhava com uma vara. Até mesmo a música, a matéria favorita de Lutero, era ensinada de forma utilitária com o fim de treinar meninos para os coros de igrejas. Em resumo: a educação das crianças era, na melhor das hipóteses, obtusa e, na pior delas, tinha algo de bárbaro. ${ }^{1}$

Durante a adolescência e juventude de Lutero, a educação permaneceu sendo rígida e dura. Com quatorze anos, o reformador ingressou numa escola em Magdeburgo, onde, segundo Defreyn, provavelmente morou numa casa para alunos mantida pelos 'Irmãos da vida comum' ${ }^{2}$. Posteriormente continuou seus estudos em Eisenach, onde, além de sofrerem com os castigos físicos, os alunos precisavam buscar meios de ganhar seu sustento. De acordo com Lindberg, "todos os alunos cantavam, literalmente, para ganhar a principal refeição do

\footnotetext{
1 LINDBERG, 2001, p. 75.

2 DEFREYN, 2004, p. 21.
} 
dia: após as aulas, eles caminhavam sem destino pelas ruas, formando coros infantis para pedir comida" ${ }^{3}$. Relatos como esse apontam para alguns problemas sociais da época, que adiante serão tratados em maior profundidade.

Essa educação severa era comum tanto na família quanto na escola e na igreja e contribuía para que, no imaginário das pessoas, se construísse uma relação de medo com Deus, pois afirmava-se que o ato de castigar alimentava a fé em um Deus que também castigava. Filipe Melanchthon, um dos colaboradores mais atuantes nas modificações que a Reforma provocou no sistema de educação, certa vez escreveu:

Empalidecíamos ao mero nome de Cristo, porque somente nos era apresentado como um juiz severo, irritado contra nós. Dizia-se-nos que, no Juizo Final, nos pediria contas dos nossos pecados, de nossas penitências, de nossas obras. E posto que não pudéssemos arrependernos o bastante, nem fazer obras suficientes, não nos restariam mais do que o terror e o pavor de sua cólera ${ }^{4}$.

Apesar da clareza que Lutero teve a respeito da realidade violenta que permeou todo o seu processo educacional, ele reconhece, em mais de uma ocasião, ter colhido bons frutos dessa situação e chega até a defender a eficácia desses castigos, desde que fossem motivados por amor e bondade. Para Lutero, "contudo, o castigo somente pode ser "castigo bondoso' e não ser expressão de raiva dos pais" ". E, ainda, "isso se evidencia também no fato de reconhecer todo o esforço de seu pai em proporcionar-lhe formação universitária: 'Os suores deste homem fizeram de mim o que eu sou" "6. Apesar dos castigos e da repressão que sofriam, a educação formal que o reformador recebeu foi privilégio de uma pequena parcela da população da época, e Lutero sabia disso.

Na universidade, a metodologia utilizada mantinha a mesma linha: estimulava o confronto, agredia o psicológico constantemente e alimentava o medo. A prática comum consistia em incentivar os debates, e esses debates permitiam a apresentação dos conhecimentos do estudante, mas também tinham o caráter de ser uma investigação em busca da verdade.

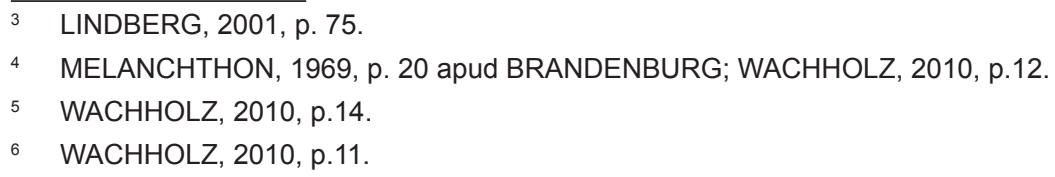


Os debatedores apresentavam suas teses e em seguida eram rebatidos por outros com provas do contrário. Apesar do caráter de confronto, o conhecimento era produzido de forma coletiva. A formulação das 95 teses foi fruto do sistema educacional da época, segundo Lindberg,

Foi justamente da forma de debate que Lutero formulou suas noventa e cinco teses, assim como muitos de seus outros escritos reformatórios. Neste e em outros aspectos a Reforma era um movimento surgido de dentro das universidades. ${ }^{7}$

A educação que Lutero recebeu influenciou o movimento da reforma da igreja assim como as mudanças que o reformador considerou necessárias para que a sociedade compreendesse o sentido e a necessidade da Reforma. Assim, vários fatores influenciaram e consequentemente atingiram o sistema educacional.

Lutero não teve o objetivo de dividir a Igreja, assim como não planejou mudar o sistema educacional. Entretanto, desde o início se mostrou um ativista pela educação de qualidade e que alcançasse maior número de pessoas. Entretanto, as experiências dele, assim como de outras pessoas envolvidas no movimento da Reforma, influenciaram as mudanças na educação, na Igreja e na vida social no geral, numa época e numa região em que praticamente todas as pessoas tinham alguma ligação com o catolicismo. Por isso, provocar alguma mudança na Igreja era sinônimo de mudanças em toda a sociedade e, assim, “[...] o reformador religioso rechaçado pela hierarquia religiosa torna-se reformador social" . Talvez Lutero ansiasse por mudanças ainda maiores. No entanto, as alcançadas foram marcantes na sociedade da época, a ponto de influenciarem a teologia e atuação cristã até os dias atuais.

No final da idade média, a pobreza era um grande problema social. A transição do feudalismo para o capitalismo, assim como a necessidade que a Igreja tinha de manter a pobreza para que sua pregação acerca de dar esmolas continuasse fazendo sentido, eram os principais agravantes do problema. De acordo com Lindberg, Lutero foi "[...] o primeiro reformador importante a escrever sobre a teoria e a prática do sistema de assistência aos pobres e do bem-estar social no início da modernidade".

7 LINDBERG, 2001, p. 76.

8 BECK, 1988, p. 84. 
As provocações de Lutero sugeriam que a missa precisava ser um espaço de comunhão e a assistência social era "[...] um exemplo específico de liturgia depois da liturgia"

As mudanças sociais foram uma bandeira pessoal de Lutero. Em escritos, assim como em posicionamentos públicos, o reformador deixava claro o quanto esse tema era valorizado por ele. O que Lutero buscou foi uma mudança nas ações e na compreensão das pessoas:

Lutero reclamava amargamente da falta de apoio da comunidade à assistência social, ao ministério e à educação. Em mais de uma ocasião, ele fez o voto solene de que não seria mais o pastor daquela comunidade, a menos que as pessoas reformassem suas vidas. ${ }^{10}$

Após a publicação das 95 teses, o movimento da Reforma se inflama, ganha mais adeptos e adeptas com influência política e religiosa. E Luteroe é solicitado como conselheiro nas ações de diferentes Conselhos municipais e dos Príncipes a partir dos convites para que ele e seus colaboradores mais próximos escrevessem as constituições eclesiásticas de diversas cidades. Esse foi um bom passo para que a Igreja buscasse a remissão pelo tempo em que contribuiu para a desigualdade social ao limitar o acesso à educação atrelado ao serviço eclesiástico.

A influência do movimento da Reforma na educação causa divergência de opiniões ainda hoje. Por um lado há dados incontestáveis da ampliação do sistema educacional alemão, inclusive nas áreas rurais, além das discussões a respeito da importância da educação formal ter chegado até pessoas com menos possibilidades financeiras, através de prédicas e de posicionamentos pessoais de Lutero. A importância que a Reforma teve no processo de tornar a escola acessível para todas as pessoas é constatada por diferentes autores. Luzuriaga, no livro 'História da educação e da pedagogia', dedica um capítulo para falar da educação a partir das reformas protestantes, onde destaca que a Reforma "deu origem à educação pública" ${ }^{11}$. O autor ainda complementa:

\footnotetext{
$9 \quad$ LINDBERG, 2001, p. 139.

10 LINDBERG, 2001, p. 154.

11 LUZURIAGA, 1959, p. 108.
} 
Nesse labor destacou-se principalmente Melanchthon, que, como veremos, foi o verdadeiro criador da educação humanista pública, não só na Alemanha, senão, por seu influxo, também no resto da Europa. No domínio da escola primária distinguiu-se principalmente outro colaborador de Lutero, Johanes Bugenhagen, que inspirou uma série de ordenações municipais nas cidades do norte da Alemanha, como Brunswick, Lübeck, Hamburgo, etc., e, após, no resto do país, com aplicação de diversos preceitos à educação primária.

Há ainda estudos que sustentam que a escola já estava se tornando independente da religião quando as ideias da reforma luterana começaram a ganhar espaço na sociedade da época Segundo Defreyn, já na baixa Idade Média, que compreendeu o período do século XI até inícios do século XVI:

[...] como as escolas que havia eram da Igreja e não contemplavam as necessidades práticas dos burgueses, estes, cada vez mais, procuravam ter ingerência sobre elas. Em muitos lugares, foram surgindo escolas nas cidades, instaladas e mantidas pelos próprios cidadãos, fossem eles comerciantes ou então os artesãos, unidos nas corporações de oficios". ${ }^{12}$

Partindo desse pressuposto, constatamos que Lutero e seus companheiros contribuíram disseminando e reafirmando esse pensamento, mas não foram os precursores do movimento de ampliação do sistema educacional.

Voltando às divergências de opinião com relação ao movimento da Reforma na educação, por outro lado, a libertação do sistema religioso católico fez com que muitas pessoas não vissem mais a necessidade de enviar seus filhos para a escola, pois não conseguiam visualizar quais as vantagens que isso traria para suas vidas, uma vez que já não aspiravam a posições no clero. A pesquisa de Vanderlei Defreyn, intitulada 'A Tradição Luterana: Sobre Lutero, educação e a história das escolas luteranas até a guerra dos trinta anos', aprofunda esse tema. Também Frederick Eby escreve,

Entre os sérios problemas com os quais se defrontou Lutero, estava o de encontrar pastores para as igrejas. Em tempos passados, os inumeráveis beneficios, prebendas e similares modos de vida sustentaram meninos

12 DEFREYN, 2004, p.14. 
pobres e jovens que estivessem estudando para o sacerdócio e outras profissões. Mas essas formas de subsistência foram arrebatadas pela torrente geral. Além disso, uma vez nomeado, o padre tinha previamente assegurada uma subsistência permanente; sob a nova ordem, não havia ainda a certeza de que o oficio de pastor garantiria a subsistência. Os pais recusavam-se a ter seus filhos estudando para uma profissão tão incerta. Como resultado dessas condições, houve deserção das universidades e a Alemanha defrontou-se com o agudo colapso de toda a cultura e ensino. ${ }^{13}$

Assim, antes de perceber que a educação primária precisava ser acessível a todas as pessoas, Lutero reconhece a necessidade de mudanças nas universidades. Em 1520, na época da sua excomunhão da igreja de Roma, o reformador escreveu, dividida em três grandes blocos, a 'Carta aberta à nobreza cristã da nação sobre a Reforma da Cristandade'. Este documento evidencia, pela primeira vez, a interligação entre a reforma da Igreja e a reforma na educação.

Em uma das vinte e sete propostas levantadas no documento, Lutero expõe suas ideias para a reforma das Universidades, que consistia em um currículo onde o ponto central deveria ser a Escritura Sagrada. Para tanto, era necessário fortalecer o ensino das línguas hebraica, grega e latina: assim se poderia ler e interpretar a Bíblia, enquanto os livros dos Pais da Igreja seriam usados como auxiliares dos estudos bíblicos e não ocupariam o lugar do livro sagrado. Destaca-se aqui o fortalecimento da criticidade como elemento da reforma educacional proposta.

Além disso, Lutero sugere que sejam excluídos das universidades os estudos de física e metafísica e os livros 'Tratados da alma e ética' de Aristóteles, por negarem a ressurreição dos mortos e defenderem a felicidade sem Cristo. Os estudantes deveriam ainda estudar Lógica, Retórica, Poética, Matemática e História. Ainda nesse documento, Lutero manifesta que não se deveria prezar pela quantidade de estudantes em detrimento da qualidade das habilidades de quem entrava nas universidades.

Após este documento em que Lutero aborda o tema da educação, constata-se um desinteresse por parte das pessoas pela educação formal motivada pela Reforma e por uma cultura 'materialista', "[...] a cultura da

13 EBY, 1976, p. 58. 
supervalorização das áreas 'materiais' em detrimento das humanidades" 14 . Nesse documento o reformador escreve: "Pois é, dizem eles, que haverão de estudar se não podem tornar-se padres, monges e freiras? Que aprendam algum ofício com que possam sustentar-se"15. Nesse contexto onde a Igreja não representa ganho financeiro e onde a pregação da Reforma contribuiu para o desinteresse pela educação formal, Lutero escreve, em 1524, 'Aos Conselhos de Todas as Cidades da Alemanha, para que criem e mantenham Escolas'.

O principal objetivo dessa carta era fomentar a criação e a manutenção de escolas e da educação numa perspectiva de longo prazo, como podemos confirmar no trecho seguinte:

Agora, o progresso de uma cidade não depende apenas do acúmulo de grandes tesouros, da construção de muros de fortificação, de casas bonitas, de muitos canhões e da fabricação de muitas armaduras. [...] Muito antes, o melhor e mais rico progresso para uma cidade é quando possui muitos homens bem instruídos, muitos cidadãos ajuizados, honestos e bem educados. Estes então também podem acumular, preservar e usar corretamente as riquezas e todo tipo de bens ${ }^{16}$.

Além de defender a educação como uma área que necessita de investimentos de longo prazo, Lutero compromete as autoridades municipais que fazem parte dos conselhos e, dessa forma, chega mais próximo dos cidadãos, aquelas pessoas que efetivamente precisavam ser motivadas a enviarem seus filhos para a escola. A carta 'Aos Conselhos de Todas as Cidades da Alemanha, para que criem e mantenham Escolas' trata de usar estratégias de comprometimento com a educação, estimulando o envolvimento e fortalecimento da participação da sociedade na vida escolar, uma visão muito semelhante ao que se espera de gestores educacionais na atualidade.

No ano de 1525, Lutero articula junto ao príncipe João, o Constante, algumas expedições de visitadores para verificar como estavam as paróquias, pastores, escolas e professores. De acordo com Defreyn, "o príncipe atendeu as solicitações de Lutero, e foram realizadas visitações para se verificar como estava a situação da vida eclesiástica e escolar.

\footnotetext{
14 WACHHOLZ, 2010, p.16.

15 LUTERO, 1995, p. 304.

16 LUTERO, 1995, p. 307.
} 
Lutero chegou a participar de algumas"17. A partir dessa ação surge o documento 'Instrução dos visitadores aos párocos', que se tornou fundamental para a organização do sistema escolar na Saxônia, além de alertar para a importância dos catecismos.

Lutero não se limita ao campo da gestão escolar, ele também faz uma análise pedagógica da eficácia dos métodos utilizados e propõe mudanças nesse campo, tornando o ambiente escolar mais próximo da realidade dos estudantes:

Ora, a juventude tem que dançar e pular e está sempre à procura de algo que cause prazer. Nisto não se pode impedi-la e nem seria bom proibir tudo. Por que então não criar para ela escolas deste tipo e oferecer-lhe estas disciplinas? Visto que, pela graça de Deus, está tudo preparado para que as crianças possam estudar línguas, outras disciplinas e História, com prazer e brincando. ${ }^{18}$

Wachholz destaca: "Nisso, podemos perceber uma das mais importantes contribuições pedagógicas de Lutero. Num contexto em que educação era sinônimo de sofrimento e até tortura, Lutero pleiteia uma pedagogia com caráter lúdico e prazeroso"19.

A descoberta de Lutero da justificação pela fé tem como consequência o sacerdócio geral de todas as pessoas que creem, compreendido como o poder concedido por Deus aos cristãos e cristãs para viver o amor por meio da fé em Cristo. Em consonância com o Sacerdócio Geral de todas as pessoas, Lutero "[...] sustentou que o serviço a Deus e ao próximo exigia uma população educada" ${ }^{20}$. Ao defender uma população educada, ousou ir além das barreiras que permitiam educar apenas meninos, pois Lutero defendia escolas também para meninas: "para que haja um sacerdócio de todos os crentes, todas as pessoas - inclusive as mulheres - deveriam saber ler" ${ }^{21}$. Obviamente, e levando em consideração todas as possibilidades que a sociedade da época permitia, a proposta educacional que Lutero defendia para meninos e meninas ainda colocava as mulheres em uma posição delicada se comparada aos dias

\footnotetext{
17 DEFREYN, 2004, p. 37.

18 LUTERO, 1995, p. 319.

19 WACHHOLZ, 2010, p.18.

20 LINDBERG, 2001, p. 155.

21 LINDBERG, 2001, p. 438.
} 
atuais. Esse fato, no entanto, não é capaz de desqualificar a iniciativa do reformador alemão.

Nos dias atuais ouvimos falar muito nos ambientes educacionais a respeito de formação continuada, baseada no oferecimento de cursos de curta e média duração para professores e professoras que já possuem formação acadêmica para a área que lecionam, mas que necessitam atualizar-se, para poderem oferecer melhor qualidade de ensino e propor novas formas de aprendizagem. Essa também foi uma das bandeiras de Lutero.

A reforma na educação recebeu e exigiu grande valorização e atenção do reformador, o qual escreveu, em 1529, os catecismos Menor e Maior, que contribuem para a educação cristã de jovens, crianças, leigos e clero. Os catecismos inicialmente surgem em forma de cartazes que eram pregados nas igrejas e escolas ${ }^{22}$, claramente em consonância com uma proposta de educação popular. Em 1530, o Reformador escreve também 'Uma Prédica Para que se Mandem os Filhos à Escola': seu objetivo era chegar às famílias através das pregações, uma vez que, com o aumento do número de universidades, um grande problema continuava sendo a motivação das famílias. O documento reforça ainda a responsabilidade do governo ao sugerir que seja obrigatória a frequência escolar e ao defender verbas para que filhos de famílias pobres pudessem estudar. Nessa "Prédica", Lutero também valorizou a função do educador e da educadora ao escrever:

De minha parte, se eu tivesse que abandonar o ministério da pregação e outras incumbências, nada mais eu desejaria tanto quanto ser professor ou educador de meninos. Pois sei que ao lado do ministério da pregação, esse ministério é o mais útil, o mais importante e o melhor. ${ }^{23}$

A tradução da Bíblia para o alemão fluente foi outra contribuição importante para as mudanças no sistema educacional, desencadeadas pela reforma da igreja. As pessoas que anteriormente conheciam as escrituras sagradas a partir das interpretações dos religiosos, agora podiam ler e interpretar os textos. Segundo Beck, a tradução do Novo Testamento para o alemão "foi publicada em setembro de 1522 e se tornou sucesso popular. Segundo alegavam os adversários, leigos incultos passaram a

22 DEFREYN, 2004, p. 39.

23 LUTERO, 1995, p. 331. 
discutir teologia com padres e monges" 24 . Este processo leva os debates, de um espaço prioritariamente acadêmico, para os meios populares. O nível de conhecimentos que as pessoas sem estudos formais tinham era inferior ao que a Academia produzia, mas o debate era reconhecidamente um aliado da construção de conhecimento.

Lutero não esteve sozinho na sua busca por um sistema educacional com mais qualidade: todo o movimento da Reforma, também nessa área, recebeu apoiadores e apoiadoras. $\mathrm{Na}$ área da educação, como citado anteriormente, Lutero contava com Felipe Melanchton e com João Bugenhagen. Melanchton foi um entusiasta do ensino do latim na escola e desaprovava o ensino do alemão, assim como considerava que aprender muitas línguas ao mesmo tempo era prejudicial. Isso tudo, apesar de ter escrito uma gramática de grego quando ainda era menino. Ele era frequentemente solicitado pelas autoridades para auxiliar na organização das escolas com seus conhecimentos.

Bugenhagen foi sacerdote e educador e teve como incumbência redigir constituições eclesiásticas para Braunschweig, Hamburgo, Lübeck, Pomerânia, Dinamarca, Schleswig-Holstein, Braunschweig-Wolfenbüttel e Hildesheim. Era conhecido por ser mais prático do que Lutero e Melanchton. Eby destaca que alguns dos regulamentos eclesiásticos escritos por ele "[...] providenciavam bibliotecas públicas e cursos de leituras públicas" ${ }^{25}$. Segundo Lindberg, para Bugenhagen,

[...] a reforma da igreja não devia ser simplesmente um decreto legal vindo de cima, mas o engajamento de toda a comunidade urbana na reforma do culto, no desenvolvimento de escolas e na criação de um novo programa de bem-estar social. Percebia-se tudo isso como algo central para a responsabilidade cristã e como dever da cidade como um todo ${ }^{26}$.

A educação, portanto, tem o duplo objetivo de servir ao culto de Deus e às necessidades do próximo ${ }^{27}$. Nesse aspecto, é possível encontrar aquele que pode ter sido o maior legado da Reforma para a educação: ao proporem que o servir a Deus deveria ser feito através das ações, motivadas pelo amor; que a liturgia do culto necessitava ser viva e atuar

\footnotetext{
24 BECK, 1988, p. 19.

25 EBY, 1976, p. 68.

26 LINDBERG, 2001, p. 154

27 LINDBERG, 2001, p. 156.
} 
entre os necessitados; ao buscarem uma educação que fosse possível para todas as crianças, meninos e meninas; ao escreverem a respeito da importância dos impostos (caixas comuns) para custear a educação das pessoas sem posses; em todas essas situações, os reformadores buscam ações práticas.

Ao propor, em uma das suas primeiras ações, um novo currículo para as universidades, onde rejeita Aristóteles e as autoridades clássicas, o que Lutero apresenta é "[...] uma mudança de paradigma, passando da epistemologia medieval baseada na dedução de autoridades textuais para uma epistemologia de indução à experiência". Mais adiante:

Nenhuma das artes pode ser aprendida sem prática. Que espécie de médico seria aquele que ficasse na escola o tempo todo? Quando ele finalmente passar a usar sua medicina e lidar cada vez mais com a natureza, vai perceber que ainda não domina a arte. ${ }^{28}$

Aspectos como este, da mudança de paradigma, que as reflexões da Reforma trouxeram para o sistema educacional da Alemanha, vieram junto com os imigrantes alemães que chegaram ao Brasil antes e principalmente após a abolição da escravatura em 1888. Esses aspectos podem ser compreendidos de melhor maneira a partir das escolas comunitárias fundadas nas colônias alemãs, especialmente no sul do Brasil, mas também no Espírito Santo. Segundo Ahlert, "assim, temos em Lutero o início da escola público-comunitária, ou seja, uma escola que deve ser tarefa dos pais, da comunidade, do Estado e de quem pode ajudar a mantê-la financeiramente" ${ }^{\prime 29}$.

Wachholz ${ }^{30}$ destaca três fatores principais que devem ser considerados para compreender o 'espírito comunitário e associativo' presente nas sociedades compostas por imigrantes alemães: 1) A composição social do Brasil no momento em que os imigrantes chegaram, baseada num modelo patriarcal; 2) A ausência de assistência por parte do Estado, condição em que os imigrantes alemães se encontraram e que forçou a criação de pequenas sociedades compostas pelas pessoas da localidade. Estas comunidades mantinham escola, igreja, cemitério, salão, venda e o que mais fosse necessário para a manutenção da vida comunitária; 3 ) A difusão na sociedade alemã do século XIX do 'espírito associativo',

\footnotetext{
28 LINDBERG, 2001, p. 439.

29 AHLERT, 2010, p. 42.

30 WACHHOLZ, 2010, p.24.
} 
que permeava a maioria das atividades como: lazer, economia, atividades culturais e religiosas, saúde.

Esse modelo de educação proposto por Lutero incentivou e construiu uma sociedade mais crítica. Isso foi possível a partir da aprendizagem das línguas necessárias para se estudar os originais do texto sagrado, pelo incentivo para que as pessoas se aproximassem das discussões políticas e desafiando e incentivando as famílias a educarem seus filhos para a vida profissional e comunitária. Esses fatores, aliados ao 'espírito comunitário e associativo' dos imigrantes, são perceptíveis nas comunidades, escolas e instituições ligadas à Igreja Evangélica de Confissão Luterana no Brasil até os dias atuais, assim como na educação informal dentro das famílias de descendentes de imigrantes alemães.

\section{Referências}

AHLERT, Alvori. Olhares prospectivos sobre a educação comunitária pública não-estatal de identidade luterana. In: BRANDENBURG, Laude Erandi; WACHHOLZ, Wilhelm (Org). Contribuições do luteranismo para a educação. São Leopoldo: Sinodal/EST, 2010.

BECK, Nestor. Igreja, sociedade, educação: estudos em torno de Lutero. Porto Alegre: Concórdia, 1988.

DEFREYN, Vanderlei. A tradição escolar luterana: sobre Lutero, educação e a história das escolas luteranas até a guerra dos trinta anos. Dissertação de Mestrado. Escola Superior de Teologia/Instituto Ecumênico de Pós-Graduação em Teologia, 2004.

EBY, Frederick. História da educação moderna: século XVI/século XX teoria, organização e prática educacionais. Tradução: Maria Angela Vinagre de Almeida, Nelly Aleotti Maia e Malvina Cohen Zaide. Porto Alegre: Editora Globo, 1976.

LINDBERG, Carter. As reformas na Europa. Tradução: Luís Henrique Dreher e Luís Marcos Sander. São Leopoldo: Sinodal, 2001.

LUTERO, Martim. Obras Selecionadas, Vol. 5. São Leopoldo, RS: Sinodal, 1995. . Educação e reforma: Lutero para hoje. São Leopoldo: Sinodal; Porto Alegre: Concórdia, 2000. 
LUZURIAGA, Lorenzo. História da educação e da pedagogia. Tradução: Luiz Damasco Penha e J. B. Damasco Penha. São Paulo: Companhia Editora Nacional, 1959.

WACHHOLZ, Wilhelm. Lutero: legados pedagógicos e comunitários. In: BRANDENBURG, Laude Erandi; WACHHOLZ, Wilhelm (Org). Contribuições do luteranismo para a educação. São Leopoldo: Sinodal/ EST, 2010.

E-mail das Autoras:

martharmaas@gmail.com katilene.willms@gmail.com 